\title{
GOLPE NA CULTURA \\ Intelectuais, universidade pública e contextos de crise no Brasil'
}

\author{
COUP IN CULTURE \\ Intellectuals, public university and crisis contexts in Brazil
}

Maria Arminda do Nascimento Arruda ${ }^{a}$

\begin{abstract}
Resumo $\mathrm{O}$ artigo analisa as relações entre as disciplinas humanísticas e culturais, no contexto da crise brasileira atual, que aprofundou a debilidade das instituições públicas de ensino superior no Brasil. Reflete, igualmente, sobre o impacto da transformação do cânone cultural moderno sobre essa área do conhecimento, ao qual se soma o enfraquecimento da esfera institucional. Nessa perspectiva, chama a atenção sobre os impasses da área, oriundos tanto do processo de valorização do domínio técnico e experimental, bem como das profissões ligadas diretamente ao mercado, que produzem novos desafios aos saberes voltados para o tratamento dos fenômenos sociais e da cultura, compelidos a repensar o seu arcabouço analítico e os seus problemas consolidados de pesquisa.
\end{abstract}

Palavras-chave Universidade; Cultura; Crise.

Abstract The article analyzes the relations between humanistic and cultural subjects in the context of the current Brazilian crisis, which deepened the weakness of public institutions of higher education in Brazil. It also reflects on the impact of the transformation of the modern cultural canon in this area of knowledge, to which the weakening of the institutional sphere is added. In this perspective, it draws attention to the impasses of the area, both from the process of appreciation of the technical and experimental domain, as well as the professions directly linked to the market, which produce new challenges to the knowledge geared to the treatment of social phenomena and culture compelled to rethink their analytical framework and their consolidated research problems.

Keywords University; Culture; Crisis.

1 Este texto resulta de exposição realizada em seminário organizado pelo Grupo de Estudos de Sociologia da Cultura: Objetos e Perspectivas, que reúne estudantes da Pós-Graduação em Sociologia da USP, em 9/12/2016. Por essa razão, o artigo aproxima-se do estilo oral da exposição. Preservei, também, o tema proposto, expresso no título.

a Professora titular do Departamento de Sociologia da Universidade de São Paulo. 
O tema Golpe na Cultura - intelectuais, universidade pública e contextos de crise no Brasil - não é de simples equacionamento. Por articular múltiplos e importantes problemas, requer o tratamento das partes, o que não exclui o exercício de relacioná-las e de interpretar o conjunto. O tema sugere, ainda, a identificação de dois pares conceituais: o de cultura e o de intelectuais; na sequência, o de universidade pública e de crise. Há uma questão oculta e não integralmente explicitada, porém importante à interpretação: os intelectuais e a cultura são componentes da universidade e a crise institucional tem posto em xeque tanto o ofício quanto o seu legado, deixando dúvidas sobre o seu lugar e pertinência numa sociedade dominada pela tecnologia e pela ventriloquia das redes sociais. Nesse contexto, o debate público qualificado perde substância, deslocando atores tradicionalmente reconhecidos, sejam intelectuais, sejam jornalistas da grande imprensa. Acrescente-se a essa gama variada de assuntos o título geral, de natureza conjuntural, que alude à reduzida importância da cultura e do seu par a ciência, na construção das políticas governamentais vigentes no Brasil; no entanto, o assunto não se reduz à mera oportunidade, pois remete a problemas de largo escopo. Desse modo, a proposta alia temáticas de diversa natureza, pois combina visadas de alcances distintos. O golpe na cultura não se desprende, portanto, de processos sociais contemporâneos; tampouco se reproduz de maneira uniforme em contextos distintos. No caso brasileiro, a atual conjuntura de crise das instituições produz expressões peculiares às questões sugeridas pelo tema.

Pensando nesses termos e sem refletir particularmente sobre cada uma das categorias de cultura, intelectual, universidade, parece ser possível admitir que, pelo menos no Brasil, a identificação entre intelectuais, universidade e cultura é datada, revelando a impossibilidade de se operar com noções substantivadas. Para explicitar a minha compreensão a respeito, esclareço que tomo a noção de intelectual no sentido comum, isto é, refere-se àqueles que produzem nas áreas das chamadas humanidades (categoria ela própria repleta de controvérsias) e das artes (se é possível encontrar algum consenso a respeito). Diante de tais questões, é aconselhável localizar algumas compreensões difundidas no meio que apontam para o universo das representações dos próprios participantes ${ }^{2}$.

2 No Brasil, Roberto Schwarz tem contribuições interessantes à reflexão sobre os intelectuais, especialmente sobre os intelectuais engajados. No ensaio Nunca fomos tão engajados, identifica o moderno intelectual "ao antifascismo europeu, ao ascenso operário do pós-guerra e chegou até ao terceiro-mundismo dos anos 6o. Salvo engano, ela pressupõe a formação burguesa do intelectual, e, de outro lado, uma semi-exclusão civil e cultural dos trabalhadores. Mais no fundo, deslocando tudo tragicamente, estava a Guerra fria”. (Schwarz, 1999, p.172). 
O entendimento de que haveria uma relação entre os intelectuais e a universidade pública, identificando-a como instituição central na produção de cultura, vicejou especialmente em São Paulo, após a fundação da USP, em 1934. Diferentemente da França, onde a imagem do intelectual se difundiu no bojo do processo Dreyfus, quando o escritor Èmile Zola denunciou a falsidade da acusação de traição do oficial, no Brasil, a institucionalização do estilo universitário paulista, ao longo dos decênios de 1940-1950, promoveu uma espécie de identificação entre cultura e intelectuais, na figura do acadêmico cônscio dos seus instrumentos disciplinares ${ }^{3}$. As distinções de constituição do intelectual moderno entre os dois países revelam diferenças marcantes da atividade: entre nós, as instituições públicas e o Estado eram, para o bem e para o mal, a garantia do exercício letrado; na França, o caráter diferenciado da cultura francesa, resultado da universalização da educação, conferiu maior independência à vida intelectual; em ambos os casos, a modernização da imprensa alterou os meios de difusão das ideias, ainda que ocorressem diferenciações quanto aos vínculos e a natureza da contribuição, originadas das particularidades dos países.

Nesse contexto de particular inserção da intelectualidade brasileira, a vida cultural percorreu um circuito primordial no ambiente das instituições, movimento pleno de consequências, uma vez que o exercício, a ação e o alcance dos intelectuais ficaram submetidos às constrições do contexto, como aconteceu durante a ditadura militar instaurada em 1964, sem desconhecer a excessiva normatização das universidades nos dias atuais, óbices poderosos à atividade, como já demonstrara a criação do sistema de pós-graduação, no bojo do regime autoritário na década de $1970^{4}$. Até a criação da universidade, a imagem corrente do intelectual confundia-se com personalidades publicamente reconhecidas, de formação eclética, comumente polígrafas, produtos híbridos do bacharel e do literato, como bem analisou Sérgio

3 O artigo J'accuse, publicado por Zola, no jornal e L’Aurore, em 13/1/1898, a respeito do episódio, é considerado um marco na construção da imagem do intelectual defensor de causas públicas. $\mathrm{O}$ acontecimento selou uma aliança entre a imprensa de opinião e a intelectualidade francesa. Nesse sentido, representa uma clivagem na história dos intelectuais e da imprensa. No Brasil, a enquete realizada pelo jornal O Estado de São Paulo, denominada Plataforma da Nova Geração, nos anos 1943-1944, sob a coordenação de Mário Neme, com 29 representantes da geração emergente de intelectuais, entre os quais os jovens acadêmicos da revista Clima, pode ser visto como uma espécie de manifesto da intelectualidade nascente. Cf: Pontes (1998), especialmente, capítulos 2 e 4 .

4 A minha perspectiva de análise sobre a universidade tem como referência a Universidade de São Paulo - USP - na qual sou professora e venho ocupando cargos de direção. Creio, no entanto, que por ser a instituição de referência no Brasil, permite que seja tomada como modelo para tratar dos problemas atuais dessas instituições de ensino superior. Esclareço, no entanto, que as minhas considerações se restringem às instituições públicas. 
Miceli ${ }^{5}$. Não obstante, a geração de 1930, dos ensaístas modernos, comumente denominados "intérpretes do Brasil", representou uma clivagem no modelo até então corrente, por sua condição de figura mista entre a personalidade cultivada e o especialista, já agora embebida no caldo cultural do modernismo, mas que já se aproximava de campos disciplinares, a exemplo de Gilberto Freyre visto como sociólogo, Caio Prado Júnior como historiador e Sérgio Buarque de Holanda como representante das duas tradições.

No pós-guerra - e independente do vínculo institucional - o intelectual identificava-se, sobretudo, com o profissional crítico, formulador de projetos para a nação, situado nos altos escalões governamentais, a exemplo do economista cepalino Celso Furtado; dos participantes do Instituto Superior de Estudos Brasileiros - Iseb, espécie de agência ideológica do desenvolvimentismo e da modernização; daqueles filiados ao Partido Comunista, denominada pelo sociólogo Marcelo Ridenti de "brasilidade revolucionária, [...] criação coletiva, [que] viria a definir-se com mais clareza a partir do final dos anos 1950, ganhando esplendor na década seguinte, seguido de seu declínio" (RIDENTI, 2010). A chamada intelligentsia mannheimiana, dos intelectuais formuladores dos destinos coletivos, distinguia-se da comunidade mertoniana, de corte acadêmico, que opunha dois modelos de projetos políticos e disciplinares e, ao mesmo tempo, diferenciava os campos culturais do Rio de Janeiro e de São Paulo (VIAnNA, 1997).

O pós-guerra no Brasil produziu um adensamento do campo cultural, na esteira do processo de modernização do país, ultrapassando os modelos até então vigentes. Os acadêmicos da Universidade de São Paulo, herdeiros de Clima, como Antonio Candido e outros de grande significado na cena cultural da cidade e os cientistas sociais congregados em torno da denominada Escola paulista de sociologia, dirigida por Florestan Fernandes, eram representantes conspícuos da mudança e diferenciação do meio (ARrudA, 2015; Pontes, 1998). Alterava-se, enfim, o estilo dos intelectuais, que, apesar do perfil universitário, aproximou-se do ideário da "brasilidade revolucionária", movimento derivado, primeiramente, da própria modernização conservadora que alijava da cena político-social as camadas populares; posteriormente, a repressão instaurada pelo regime autoritário sobre a instituição, especialmente após a promulgação do Ato Institucional número 5, de 13 de dezembro de 1968, provocou um aprofundamento da crítica e ampliou a adesão a projetos de esquerda. O modelo do intelectual-acadêmico, formado nos

5 Em vários trabalhos, Sérgio Miceli explorou em diversos ângulos o problema. Cf: MicELI, (1979); (2001). 
anos 1950-1960, nos quadros das instituições públicas, disseminou-se, porém, entre as gerações universitárias seguintes, por aliar docência, pesquisa e reflexão, práticas que não estiveram alheias à agenda política do momento ${ }^{6}$. Não por casualidade, a afirmação dessa intelectualidade dependeu da condição pública dos seus institutos, mas que não estava liberta das flutuações derivadas da política e dos programas governamentais.

Em consequência, tal conjunção não dispensa, antes pressupõe, a vivência de problemas e limitações: a instituição universitária, embora ofereça condições ao desenvolvimento da vida intelectual, tende a circunscrevê-la aos parâmetros do previsível. Mesmo que se rejeite a noção de intelectuais demiurgos, tipicamente mannheimiana e hoje questionada, não há como desconhecer que o exercício intelectual e a produção cultural encontram nas universidades o seu suporte central. Esse fenômeno mundial, marcadamente característico no Brasil, expressa tanto modalidades de profissionalização da atividade, quanto a propagação de requisitos formais de construção da reflexão, condições de base da produção das linguagens e da construção das legitimações. As universidades passaram a desempenhar o papel que, no passado, a imprensa tivera, enquanto meio de sobrevivência, de criação de reputações e classificações, de hierarquias e prestígios7 ${ }^{7}$. Acontece, porém, que tais processos ocorrem no interior de instituições excessivamente normatizadas, pois são grandes organizações burocráticas reguladoras do próprio modo de se conceber a prática acadêmico-científica, como se percebe nos requisitos ao financiamento das pesquisas, nas avaliações disseminadas, inclusive entre pares. $\mathrm{O}$ resultado é a criação de imensos organismos de administração, guiados por normas e por regras anônimas, semelhantes a outros congêneres públicos ou privados. As instituições da cultura, como revelou Adorno há mais de meio século, quando se burocratizam operam sob a mesma lógica das administrações; a sua contra face é o saber especializado (Adorno; HorkHEIMER, 1971).

Nessa perspectiva, a identificação entre intelectuais e universidade rearranja todo um universo de representações sobre a propalada autonomia dos seus representantes. Paradoxalmente - e essa é uma questão pouco difundida -, a comunidade universitária costuma propugnar por mais regulamentação, com o fito de lhe garantir o atendimento das suas demandas e ampliação dos suportes insti-

6 Para Roberto Schwarz, nesse período, o país estava “irreconhecivelmente inteligente”. (SchwARZ, 1987). Ver também o ensaio citado, "Nunca fomos tão engajados”, de 1999.

7 Processo semelhante de institucionalização ocorreu com as artes, uma vez que "a arte contemporânea quase não existe sem um texto assinado ... por um especialista”. Essas mudanças, segundo a socióloga Nathalie Heinich, correspondem à passagem de "uma arte 'orientada pelo mercado', para uma arte 'orientada pelo museu”.' (HeINICH, 2014, p. 379-381). 
tucionais, particularmente em áreas inseguras em relação à inserção profissional, pois ocupam posições distanciadas do mercado. Nesse terreno movediço, a posição das Humanidades, das Ciências Sociais stricto sensu, mesmo das Artes, ou seja, disciplinas que trabalham com os sentidos e a cultura, é de franca desvantagem, pois são dependentes de decisões que emanam da administração, apresentadas de modo racional e neutro, forma velada de manifestação de propósitos francamente políticos. Até por isso, ocorre, sobretudo nessas áreas, tendência ao revigoramento das reivindicações. Nesse quadro, as disputas internas ao campo e externamente a ele se acirram, envolvidas em bandeiras de legitimidade intelectual, de concepção de universidade oriunda de visões que desconsideram, muitas vezes, as mediações. A vocalização de tais demandas é amplificada pela crise de financiamento das universidades públicas brasileiras. As contendas em torno das narrativas mais legítimas acabam por ocupar grande parte do cotidiano institucional, sugando energias potencialmente criadoras. As chamadas disciplinas intelectuais, cujas posições são de franca desvantagem frente ao mundo da tecnologia, das redes sociais, da valorização da inovação produtiva, do empreendedorismo, do domínio da técnica sobre a cultura, veem sua identidade questionada. Os efeitos dessas transformações provocam uma re-hierarquização entre domínios do conhecimento, com predomínio das disciplinas técnicas e de mercado.

Esse fenômeno interno às universidades - e que reposiciona o lugar das disciplinas da cultura no âmbito da instituição - não se esgota no circuito acadêmico, pois as próprias transformações atingem outras organizações, a exemplo da grande imprensa, hoje acicatada pela difusão das informações que grassam nas redes sociais, nas formas instantâneas de transmissão das notícias, na horizontalidade da veiculação. Diante dessa realidade, os meios de informação, organizados em poderosos conglomerados, são levados a buscar outros nichos para afirmar a sua influência, tendo em vista que são incapazes de concorrer com a instantaneidade característica das redes. Nesse cenário de agências variadas e de expansão dos produtores, independentemente da qualidade da informação, a grande imprensa reage criticando as áreas acadêmicas, especialmente aquelas dedicadas ao tratamento da cultura. Essas reações são componentes do mal-estar da imprensa em relação ao alcance das informações difundidas pelos meios tecnológicos, pois, ainda que estas sejam superficiais, indiferenciadas e se construam como se fossem expressão veraz dos acontecimentos, produzem fortes impactos na sociedade. Quanto à universidade, constrangida por requerimentos de vária ordem e fragilizada frente à crise, tateia na busca de afirmar a natureza específica, igualmente abrangente, da sua vocação. Em todo caso, dispensa-se o papel dos mediadores 
na construção das opiniões, assumindo o equívoco de considerar o mundo social transparente e auto-evidente.

Nesse contexto, as disputas por legitimidades e reputações resultam em relações conflituosas entre os atores mais habilitados a garantir certos padrões de qualidade, como o são os intelectuais e os jornalistas dos veículos de prestígio, provocando dissensões e alterando parcerias tradicionais. A rigor, as transformações em curso na sociedade atingem a todos - e nem poderia ser diferente. Nas universidades, persegue-se um novo modelo institucional, mas de resultados imprevistos, no qual especialmente as disciplinas intelectuais e da cultura parecem não vislumbrar, tanto a sua posição no todo, quanto o caráter legítimo da sua contribuição. A grande imprensa busca formas alternativas de transmissão das informações, seja aderindo aos meios eletrônicos, como tentativa de acompanhar a instantaneidade da notícia, seja esboçando novas modalidades de transmissão, particularmente visível no jornalismo analítico televisivo.

Esse conjunto geral de problemas - se referido ao caso brasileiro e tomando como paradigma a Universidade de São Paulo - comumente manifesta-se nos discursos triunfantes a respeito da relevância e importância da USP, vista como a mais exitosa instituição acadêmica brasileira, mas ressalta a sua defasagem vis a vis os grandes centros mundiais de ensino e pesquisa. Esses discursos híbridos, aparentemente incompatíveis, escondem na verdade representações de agentes diversamente situados. No âmbito interno, as afirmações que enfatizam a crise da universidade originam-se de atores responsáveis pela alta administração que, ao remarcarem as dificuldades de financiamento, justificam os ajustes orçamentários horizontais, sem considerar as particularidades, processo francamente desfavorável às áreas da cultura, como se percebe no conteúdo das mensagens de celebração que exaltam os avanços das ciências experimentais, tecnológicas e aplicadas. Na cena exterior, seguidamente a grande imprensa noticia a crise das universidades como fruto dos próprios impasses do modelo, quando não atribui à má gestão dos docentes o uso perdulário dos recursos, resvalando para julgamentos que desconsideram as limitações impostas à instituição. Perdidas em meio a esse cipoal de disputas, as disciplinas humanísticas passam a não vislumbrar o seu lugar nesse emaranhado de posições díspares, quando não contraditórias, sendo as áreas mais atingidas pelas políticas regulatórias e pelos reclamos por maior eficiência administrativa, segundo critérios de resultados quantitativamente aferidos ${ }^{8}$.

8 Advirto que utilizo noções substantivas para referir-me às áreas disciplinares, bem como às instituições, apenas para encaminhar o raciocínio. Não desconheço que se trata da ação de atores situacionalmente posicionados. 
As Humanidades reagem, muitas vezes, desobservando representações sedimentadas sobre a natureza do métier acadêmico e profissional, ruptura manifesta em reivindicações de puro corte corporativo, afastando-se da deontologia consagrada; atitudes de isolamento e de recusa silenciosa são o anverso do ativismo recorrente, mas orientam condutas de afastamento e de alienação dos reais problemas a serem enfrentados. Nesse quadro incerto, pode-se inquirir sobre as razões subjacentes às representações mais comuns e perguntar-se sobre as motivações e interesses diversos que movem o conjunto. Finalmente, não há como desconhecer que as áreas técnicas e as profissões de mercado não possuem a mesma relação com a instituição daquela das disciplinas humanas e básicas. Por esse motivo, a relação que mantêm com a tradição que regulou o modelo consagrado de universidade é quase inexistente. Enquanto nas disciplinas humanísticas e básicas o horizonte profissional é nublado e, em geral, preso às demandas de caráter social e público como a docência, a relação dos setores diretamente profissionais está comprometida com o mercado. Deriva daí a diversidade das representações sobre a situação institucional.

A rigor, a denominada crise da universidade é mais afeita aos setores mais fragilizados profissionalmente, afetando de modo inequivalente o conjunto. As Humanidades costumam enfrentar esse estado de coisas apegando-se a um modelo do passado, que também já não possui a mesma força para corresponder aos anseios que grassam nesse ambiente de expectativas inseguras; protegem-se preservando uma imagem de universidade que, talvez, só tenha existido como ideário, aprofundando o isolamento e alimentando a autorreferência, estado inibidor à reflexão sobre as múltiplas questões afeitas a esse campo do conhecimento. Os desafios a serem enfrentados são de grande monta que, a meu juízo, exigem repensar os nossos próprios problemas e objetos de pesquisa. Alterar, em suma, a hierarquia dos temas e ousar propor novas perguntas e enquadramentos analíticos.

Se o impacto da tecnologia de informação e da internet redefiniu estruturalmente a esfera pública, ${ }^{9}$ igualmente relevante tem sido a prolífera produção cultural localizada nos bairros periféricos e pobres das grandes metrópoles, fazendo emergir uma gama variada de propostas e de produtores localizados à margem das instituições acadêmicas de prestígio. A chamada cultura da periferia, representada pela literatura marginal, o cinema da quebrada, o teatro do oprimido, apenas para nomear as linguagens mais próximas do cânone acadêmico, tem abalado os alicerces da cultura letrada. Não se pode desconhecer, assim, a interferência

9 Cf: Martucelli, 2015. 
dessa vasta e diferenciada produção cultural na cena contemporânea, construída à margem das universidades e das suas concepções dominantes, embora esteja suscitando o aparecimento de novos objetos de pesquisa, em meio à variegada produção de trabalhos e de teses acadêmicas oriundas da institucionalização da pós-graduação. Esses novos movimentos no campo da cultura, ainda insuficientemente compreendidos, questionam representações consagradas, rompem consensos, aprofundam uma espécie de sentimento de impotência, de derrota e de crise geral no âmbito das disciplinas humanísticas. Resultam desse processo visões que tendem a confundir projetos de universidade em oposição, com personalização das responsabilidades; a prática política legítima na academia transmuta-se em contendas pessoais, dificultando a construção de alternativas.

O que parece estar no horizonte é o surgimento de um fenômeno mundial de outra ordem, que tenho denominado de mudança do cânone cultural moderno, levando de roldão os significados atribuídos aos intelectuais com os quais estávamos familiarizados e os nossos entendimentos a respeito da cultura, que, no Brasil, esteve identificada com a figura do intelectual cônscio da sua missão civilizatória, que se exprime por meio do ensaismo crítico. Esta forma de reflexão foi redefinida, mas não integralmente superada, ao longo do processo de institucionalização da produção acadêmica, identificada sob a categoria dos estudos sobre a formação (ARRUDA, 2017). Apenas com a constituição e expansão do sistema de pós-graduação alterou-se o modelo do intelectual, especialista em temas circunscritos, analiticamente competente no seu campo disciplinar. As visões abrangentes tornaram-se, no entanto, campo específico de pesquisa e especialidade reconhecida, voltados ao tratamento de autores e obras marcantes da nossa tradição, classificados no rol de estudos do pensamento social brasileiro, história dos intelectuais, sociologia da cultura, sociologia dos intelectuais. ${ }^{10}$ Esses trabalhos, na medida em que põem em escrutínio os intelectuais e a sua produção, desmitificam a própria prática, sendo componentes e sintomas do processo de perda de aura da atividade intelectual.

Ao lado disso, o legado moderno - que foi tão marcante na construção da nossa herança letrada - é posto em questão, no contexto em que a globalização, a financeirização do hipercapitalismo destruíram o nosso ideário de nação moderna, para cujo concurso os intelectuais brasileiros foram centrais. Hodiernamente, são os especialistas, técnicos do ajuste ao mundo global, isto é, ao capitalismo

10 Um balanço sobre os estudos da Formação, Cf: ArrudA, Maria Arminda do Nascimento, 2018; sobre a sociologia da cultura, idem, 1. 
mundial com seus movimentos avassaladoramente desintegradores, os principais vocalizadores dos destinos do país. Reversivamente, os ilustrados do passado estão submetidos ao exame sistemático das novas gerações; em decorrência, surgem trabalhos críticos que propõem a revisão, quando não a superação, do chamado "paradigma da formação", posto sob os holofotes da realidade global.

O que se percebe, é que à instabilidade internacional, de certa forma comum a todos os países, embora com efeitos muito diferenciados, agregou-se no Brasil a presença de instituições em frangalhos, aprofundando-se os impasses do nosso presente. Nesse quadro de falência das promessas civilizatórias e de domínio autocrático, para me apropriar do conceito desenvolvido por Florestan Fernandes (1975), naufragam tanto a cultura, quanto o domínio intelectual, debilitando a esfera institucional, haja vista os dilemas recentes da pasta da cultura, bem como das universidades públicas, patentes nos problemas de financiamento e em propostas que alteram o sentido das instituições públicas. Não por casualidade, as bandeiras civilizatórias, comprometidas com os valores modernos e cosmopolitas da nossa cultura e com o desenvolvimento da ciência, foram deslocadas e substituídos por exigências da internacionalização da produção acadêmica, e da inovação dirigida ao sistema produtivo.

A antiga ideia do moderno e da modernização que pressupunha o tratamento do modernismo desvaneceu-se na esteira dos nossos problemas, aos quais se somam manifestações regressivas internas e externas. Estas, particularmente, foram solapadas pela cultura de mercado que vem absorvendo as vanguardas pelo menos desde o pós-guerra, como revela Raymond Williams (1997), processo que, ao combinar-se às realidades particulares, produz efeitos de intensidades diferenciadas, retrovertendo sobre as condições de desenvolvimento da área cultural. Para um autor da envergadura de T. J. Clarke, vivemos a plena crise do tempo, porque estamos imersos no caldo de cultura resultante do rompimento dos padrões modernos, minando os alicerces da modernidade civilizatória (CLARKE, 2013). No mesmo sentido, para Pierre Bourdieu

a cultura está ameaçada, porque as condições econômicas e sociais nas quais ela pode se desenvolver estão profundamente afetadas pela lógica do lucro nos países avançados, onde o capital acumulado, condição da autonomia, já é importante, e, a fortiori, nos outros países (Bourdieu, 2001, p. 81). 
No entanto, considero que outras questões relevantes e que remetem para contextos particulares presentes como os do Brasil atual exigem a compreensão das conjunturas econômica e política do país. A relação de identificação entre a intelectualidade nativa de esquerda e o Partido dos Trabalhadores (PT), que participou da criação da agremiação, questionou a condição dos intelectuais engajados, quando foram obrigados a se defrontar com ações dissolventes cometidas por expoentes partidários. Apesar do conhecido anti-intelectualismo do seu líder máximo, Lula, a criação do PT representou um alento para as esquerdas brasileiras e esperança para as internacionais, vergastadas pelas denúncias do Gulag, do totalitarismo soviético, da perda de aura da revolução cubana. Na França, a morte de Sartre já simbolizara o recuo da personalidade do intelectual engajado; com a eleição do socialista François Mitterrand, em 1981, ocorreu nítida separação entre a esquerda política e a esquerda intelectual, entre poder político e poder espiritual (WINOCK, 2000).

A vitória do PT no Brasil, renovou os ânimos de uma intelectualidade crítica e de esquerda, que, diga-se de passagem, já mantinha certa relação simbiótica entre a reflexão e os compromissos políticos, porém, o êxito não dirimiu completamente os conflitos, mesmo durante o período mais hegemônico do partido. A mescla entre a organização e o aparelho do Estado levou a dissidências e discordâncias, agravadas, posteriormente, com as denúncias de corrupção, dos vários processos judiciais e da revelação de utilização de métodos discutíveis no exercício do poder. A crise institucional, já inaugurada no segundo Governo de Dilma Rousseff, em 2014, se questionou o apoio da intelectualidade nativa ao projeto do PT, os seus desdobramentos atingiriam a legitimidade da cultura. Essa "experiência da derrota" para lembrar o verso do grande poeta inglês, Milton, aprofunda-se ao se mesclar às transformações estruturais do tempo, que, de per se, já impõem mudanças profundas ao exercício ilustrado. Essa "esquerda sem futuro" segundo o desalentado programa de Clarck (Idem, ibidem), é fenômeno mundial, mas com expressões particulares no Brasil, porque esgarça o compromisso social da intelectualidade da terra.

Do ângulo da universidade, aprofunda-se o fosso que separa as chamadas Humanidades das áreas experimentais e tecnológicas, com clara desvantagem para as primeiras, dada a característica das últimas de seguirem o movimento social dominante, tornando-as, no entanto, debilitadas para cumprir o papel de inquirirem-se sobre as dimensões éticas das pesquisas e de se indagarem sobre os seus fins. As disciplinas da cultura, todavia, não se fortalecem; contrariamente, tornam-se prisioneiras do cipoal de regimentos que, no limite, inibem a criativi- 
dade e apequenam o seu potencial de crítica do presente, atributo distintivo da sua reflexão. Por essa razão, a crise que a todos alcança tem efeitos mais deletérios para as áreas da cultura, por incidir, diretamente, sobre o sentido da sua reflexão.

Penso, no entanto, ser possível, e mais do que isso, imprescindível, rever todo o arcabouço disciplinar, o que levaria a reconsiderar os sentidos da reflexão crítica, dos estudos da cultura, da condição dos intelectuais e das universidades na produção do conhecimento. Encontrar, enfim, um outro telos para enquadrar o movimento de ruptura do cânone cultural herdado. As profundas transformações portam impactos imprevisíveis, a exemplo do abalo sofrido pela cultura clássica com a emergência e posterior domínio do cristianismo. Construir um outro lugar da reflexão levaria a inquirir sobre esses deslocamentos, tensões e abalos que têm desarticulado o papel dos intelectuais nas sociedades contemporâneas, transformado a cultura e questionado as instituições de suporte. O movimento produzirá, certamente, mudanças ponderáveis nos sentidos compartilhados, desestabilizará as nossas certezas, mas poderá abrir espaços à retomada de certos compromissos primordiais; pelo menos romperá a perplexidade reinante, em nome da necessidade de imaginar novos projetos civilizatórios.

\section{REFERÊNCIAS BIBLIOGRÁFICAS}

Adorno, Theodor; Horkheimer, Max. "Cultura y administración”. In: Adorno, Theodor; Horkheimer, Max. Sociologica. Madri: Taurus, 1971, p. 69-98.

Arruda, Maria Arminda do Nascimento. Pensamento brasileiro e sociologia da cultura: questões de interpretação. Tempo Social, v. 16, n. 1, p.107-118, jun. 2004.

. Metrópole e Cultura. São Paulo no meio Século XX. São Paulo: EDUSP, 2015. .El concepto de formación en tiempos críticos: esbozo de refléxion. Sociológica, vol. 32, n. 90, p.47-68, 2017.

. The contemporary relevance of Florestan Fernandes. Sociologia e Antropologia, v. 8, n. 1, p. 47-58, 2018.

Bourdieu, Pierre. “A cultura está em perigo”. In: Contrafogos 2: por um novo movimento social europeu. Rio de Janeiro: Zahar, 2001, p. 80-97.

Clarck, Timothy James. Por uma esquerda sem futuro. São Paulo: Editora 34, 2013.

Heinich, Nathalie. Práticas da arte contemporânea: uma abordagem pragmática a um novo paradigma artístico. Sociologia e Antropologia, v. 4, n. 2, p. 373390, 2014.

Martucelli, Danilo. “Esfera pública, movimentos sociais e juventude”. In: SorJ, Bernardo; FaUsto, Sérgio (Org). Internet e mobilizações sociais: transformações do espaço 
público e da sociedade civil. São Paulo: Centro Edestein de pesquisas sociais e Instituto Fernando Henrique Cardoso, www. Plataforma democrática, 2015.

Miceli, Sérgio. Intelectuais e classe dirigente no Brasil (1920-1945). São Paulo: Difel, 1979. Intelectuais à brasileira. São Paulo: Cia. das Letras, 2001.

Pontes, Heloisa. Destinos mistos. Os críticos do grupo clima em São Paulo (1940-68). São Paulo: Cia. das Letras, 1998.

RidENTI, Marcelo. Brasilidade revolucionária. Um século de cultura e política. São Paulo: Editora Unesp, 2010.

Schwarz, Roberto. "Nunca fomos tão engajados'. In: Schwarz, Roberto. Sequências brasileiras ensaios. São Paulo, Cia das letras, 1999, p. 172-177.

Williams, Raymond. "When was modernism?” In: Williams, Raymond. Politics of modernism: Agaisnt the new conformists. Londres: Verso, 1997, p. 31-36. 